\title{
Por que empregar a Análise Retórica no Jornalismo?1
}

\section{Luciano Klöckner*}

Resumo: A Análise Retórica (AR) é utilizada mais em estudos da área da comunicação ligados a Publicidade e Propaganda, e a Relações Públicas, mas as pesquisas com objetos jornalísticos não parecem ocorrer com freqüência. Quais seriam as razões deste quase abandono da AR pelo Jornalismo? Talvez o distanciamento da Retórica se explique pela associação única com as figuras de linguagem, isto é, o floreio verbal aplicado em alguns discursos vazios. Ou ainda à falta de conteúdo nas mensagens retóricas. Em vista das possibilidades referidas, pretende-se refletir sobre a questão e, ao mesmo tempo, apresentar proposições para que os pesquisadores do jornalismo lancem mão da Retórica na análise dos discursos, visando a averiguar a presença da persuasão e da argumentação nas mensagens divulgadas no jornal, no rádio, na televisão, na internet e nas demais mídias sociais. Palavras-chave: Retórica; Jornalismo; análise do discurso.

Resumen: E1 Análisis Retórico (AR) es utilizado principalmente en las investigaciones en el campo de la comunicación relacionados a la Publicidad y Propaganda y a las Relaciones Públicas, pero en los estudios que tienen como objeto el periodismo no suelen ocurrir con frecuencia. ¿Cuales serian las razones de este casi abandono del AR por el Periodismo? Quizás el alejamiento de la Retórica se pueda explicar por la asociación única con las figuras de lenguaje, eso es, el floreo verbal que se aplica en algunos discursos vacios. $\mathrm{O}$ aun a la falta de contenido en los mensajes retóricos. Observando esas posibilidades, el autor busca discutir esta cuestión mientras que presenta proposiciones para que los investigadores del periodismo utilicen la Retórica en el análisis de los discursos, con el objetivo de averiguar la presencia de la persuasión y de la argumentación en los mensajes divulgados en periódicos, en la radio, en la televisión, en la internet $\mathrm{y}$ en las otras medias sociales.

Palabras clave: Retórica; Periodismo; Análisis del do discurso 
Abstract: The Rhetorical Analysis (AR) is most used, in the area of communication studies, related to Advertising and Public Relations, but research on journalistic objects do not appear to occur frequently. What are the reasons for the virtual abandonment of the AR for journalism? Perhaps the reduced approximation of the Rhetoric is explained by unique association with the figures of speech, ie the verbal flourish applied in some empty speeches. Or the lack of content in rhetorical messages. Considering these possibilities, the author intend to reflect on this issue and at the same time provide propositions for journalism researchers to use Rhetoric in discourse analysis in order to ascertain the presence of persuasion and argumentation in messages posted on newspaper, radio, television, the Internet and in other social media.

Keywords: Rhetoric; Journalism; Discourse analysis

\section{Começo: o que é Retórica?}

A priori é importante investigar, feito arqueólogo, os primór-

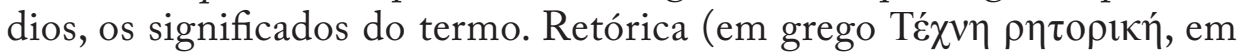
latim Ars Rhetorica) é um texto do filósofo grego Aristóteles, de Estagira. É composto por três livros (I: 1354a - 1377b, II: 1377b - 1403a, III: $1403 \mathrm{a}$ - 1420a). Ao que tudo indica, o objetivo de Aristóteles com a Retórica foi oferecer tratamento eminentemente filosófico ao tema em oposição ao tratamento descuidado que retores e sofistas daquele tempo conferiam ao tema. De modo mais específico, muitos acreditam que a reflexão aristotélica foi uma resposta à concepção retórica de Isócrates de Atenas. Ao contrário de Platão, que no diálogo Górgias condena a retórica e no diálogo Fedro subordina a retórica à filosofia, a investigação aristotélica procura conferir autonomia para a técnica retórica, desvinculando-a da vigilância da filosofia (coisa que Platão discordava por considerar a retórica eticamente perigosa).

Para Aristóteles, "a retórica é a outra face da dialética; pois ambas se ocupam de questões mais ou menos ligadas ao conhecimento comum, e não correspondem a nenhuma ciência em particular. $\mathrm{O}$ seu objeto é o verossímil ou o provável, diferenciando-se da demonstração ou analítica, que trata do necessário e do verdadeiro. De fato, todas as pessoas de alguma maneira participam de uma e de outra, pois todas elas tentam 
em certa medida questionar e sustentar um argumento, defender-se ou acusar" (Rhet., I, 1354a).

No livro I, Aristóteles analisa e fundamenta os três gêneros retóricos: 1) Deliberativo, que procura persuadir ou dissuadir, orientando para uma decisão futura. O seu lugar é nas assembleias e nos conselhos; 2) Judicial/Forense, que acusa ou defende a propósito de uma ação passada, determina o que é justo ou injusto. É típico dos tribunais; e 3) Epidêitico/Epidíctico, que elogia ou censura atos contemporâneos. Perelman e Olbrechts-Tyteca atribuem ao gênero epidêitico função essencial para revitalizar os valores da comunidade, considerando que eles estão no fundamento de todas as formas de argumentação. Segundo Aristóteles, sua temporalidade característica é o presente.

De acordo com Perelman e Olbrechts-Tyteca (1996, p. 24), a distinção dos gêneros oratórios e persuasivos é puramente prática, possuem "falhas e insuficiências manifestas", mas ainda assim têm o mérito de salientar a importância que o orador deve atribuir às funções do seu auditório.

Com o passar dos anos há o entendimento quase geral de que a Retórica limitou-se a uma técnica ou arte do dizer bem, muito embora Aristóteles definiu-a mais do que isso: como dynamis (poder, capacidade) e não apenas techne. Leach (2002, p. 293) refere este desfiguramento de sentido que vem abalando uma disciplina acadêmica histórica, ao afirmar que cotidianamente "algo retórico é equivalente a uma coleção de mentiras ou meias verdades”. De fato, para ele, o termo retórica apresenta três definições básicas: "Retórica I: ato de persuadir; Retórica II: a análise dos atos de persuasão; Retórica III: uma cosmovisão sobre o poder persuasivo do discurso".

Conforme Leach, as etapas da análise compreendem: 1) Estabelecer a situação retórica do discurso a ser analisado; 2) Identificar os tipos de discurso persuasivo empregando a teoria da estase (levando em conta os tipos de discurso judicial/jurídico ou forense, deliberativo e epidêitico/epdíctico; 3) Aplicar os cinco cânones retóricos de Cícero (invenção: ethos, pathos e logos; disposição; estilo: metáfora e analogia/ metonímia e sinédoque; memória e apresentação); e 4) Revisar e aprimorar a análise, empregando as orientações reflexivas.

Em relação ao primeiro passo da Análise Retórica, isto é, o estabelecimento da situação retórica do discurso, Leach (2002, p. 296) cita que o contexto é o primeiro ponto a ser levado em consideração. $\mathrm{O}$ segundo é o de identificar a qual dos três gêneros persuasivos pertence 
o discurso, se judicial/forense (dos tribunais), se deliberativo (arena política) ou epidêitico/epdíctico (temas contemporâneos), pois, independentemente do tipo de discurso, a sua função persuasiva é evidente, na medida em que eles (os discursos) sempre serão utilizados para formar opinião.

A terceira fase da análise tem por base a aplicação dos cinco cânones da retórica: a) Invenção - que é a origem dos argumentos: ethos, a credibilidade do autor; pathos, o apelo à emoção; e o logos, a lógica dos argumentos; b) Disposição - a organização do discurso; c) Estilo - o modo próprio de apresentar o discurso: metáfora e analogia; e metonímia e sinédoque; d) Memória - acesso do locutor ao conteúdo da fala; e e) Apresentação - que explora a relação entre a propagação de um trabalho e o seu conteúdo.

Cabe observar que Leach admite fraquezas na análise retórica, citando, por exemplo, "a que altura a análise da persuasão não se torna, ela mesma, persuasiva?" (2002, p. 294); "como distinguir a boa da má retórica como preconizava Platão e o próprio Aristóteles?” (2002, p. 294-295); "como não cair no perigo da falácia intencionalista, que busca reconstruir tão somente a intenção do autor sem levar em conta o contexto e a totalidade do discurso?" (2002, p. 297). Ademais, ele ressalta que "o objetivo da retórica nunca é ser científica, ou capaz de categorizar a persuasão para todos os tempos e lugares", mas está na "sua proximidade, sua habilidade de falar sobre o particular e o possível e não sobre o universal e o provável” (2002, p. 298).

De acordo com o autor, "por sua própria natureza, a análise retórica é um ato discursivo", pois "está produzindo argumentações sobre argumentações”. Embora se encaixe perfeitamente para o estudo de discursos completos e convencionais (editoriais, falas de políticos etc.), Leach supõe que documentos oficiais e discursos orais do cotidiano "podem ser analisados retoricamente, com efeitos muito positivos". Para ele, a principal fraqueza da análise retórica está na "amplitude de seus formalismos"; entretanto compreende que, se assim não fosse, seria "inexequível e provavelmente desinteressante”.

Para garantir qualidade à pesquisa, Leach lembra alguns predicados que devem ser considerados pelo analista: - a retórica não reivindica verdades universais e mede o sucesso ou o fracasso constatando se persuadiu ou não o público visado em seu tempo e espaço reais; - se aceitarmos a possibilidade de a verdade estar condicionada ao espaço e 
ao tempo, deve-se dar atenção ao particular e não ao geral; - uma boa análise retórica não hesita em fazer afirmações normativas; - é importante para o pesquisador prestar atenção aos pressupostos do seu campo de estudos; - o argumento utilizado deve se fundamentar na qualidade e no caráter da evidência apresentada; - levar sempre em consideração o processo de construção de conhecimento e as próprias limitações de cada campo.

\section{Conexão com o Jornalismo: a estrutura do campo retórico}

Editada em 1958, a obra clássica Traité de LAArgumentation: La Nouvelle Rhétorique ${ }^{2}$, dos professores da Universidade de Bruxelas, Chaïm Perelman e Lucie Olbrechts-Tyteca, sustenta a estrutura do campo retórico a ser utilizada na AR das mensagens, estabelecendo uma conexão com o Jornalismo. Lançando mão da analogia jurisprudencial para compreender o processo argumentativo, segundo observação de Cardoso e Cunha (2004), o conteúdo da obra permanece atual, mais de 50 anos após a primeira edição, pelas possibilidades de análise do discurso retórico oferecidas para o exame das mensagens jornalísticas.

Perelman e Olbrechts-Tyteca fornecem subsídios para a análise retórico-jornalística, embora apresentem objetivos que contemplem de forma mais específica o âmbito jurídico e o texto escrito. No entanto, na própria introdução da obra (1996, p. 8), os autores admitem que: "as mesmas técnicas de argumentação se encontram em todos os níveis, tanto no da discussão ao redor da mesa familiar como no do debate num meio muito especializado."

O grande mérito dos dois autores foi resgatar a ideia de diferentes tipos de auditório, presente na retórica clássica de Aristóteles, preocupando-se mais com os esquemas argumentativos empregados do que pelo "desenrolar completo de um debate" (p. 9). Ambos introduzem também termos como verossimil, plausivel e provável, iniciando uma crítica pós-moderna da razão (CARDOSO E CUNHA, 2004, p. 39), que considerava tão somente a busca da "verdade", conforme refere Boaventura de Sousa Santos:

A natureza retórica do discurso científico é definida pelo tipo de argumentos considerados válidos e mais válidos no seio do auditório relevante desse discurso. A identificação e 
a sistematização desses argumentos é o objetivo da retórica. (...) o domínio da argumentação é o razoável, o plausível, o provável, e não o certo ou o falso. A marginalização da retórica a partir de Descartes dá-se quando este, em O Discurso do Método, declara que uma das regras do novo método é considerar falso tudo aquilo que é apenas provável (...) Do ponto de vista retórico, a verdade é o valor daquilo que se pretende apresentar como incontroverso (SANTOS, 1989, p. 98 e 101).

Para Perelman e Olbrechts-Tyteca (1996), toda a argumentação visa a aumentar a adesão dos espíritos e, por isso mesmo, pressupõe a existência de um contato intelectual (idem, p. 16). E para argumentar é necessário ter apreço pela adesão do interlocutor, pelo seu consentimento, pela sua participação mental (idem, p. 18). Outra condição entre o orador e o auditório é perguntar por que alguém vai ouvir, uma vez que os fatos não falam por si (idem, p. 20), o que demanda uma certa qualidade para tomar a palavra e ser ouvido. Também é fundamental definir o auditório que, para Perelman e Olbrechts-Tyteca (idem, p. 22), "é o conjunto daqueles que o orador quer influenciar em sua argumentação". Ambos entendem que a variedade de auditórios é quase infinita, mas, em regra geral, subdividem-se em três: o auditório universal, o formado pelo diálogo com o interlocutor e o composto pelo próprio sujeito.

No caso específico dos meios de comunicação, o ideal é atingir um auditório universal, embora este seja composto por vários auditórios particulares, ou, como observam os autores, "o auditório universal é constituído por cada qual a partir do que sabe de seus semelhantes, de modo a transcender as poucas oposições de que tem consciência" (idem, p. 37). Assim, os veículos de comunicação social, como o jornal, o rádio e a televisão, por exemplo, atuam em faixas de público e de programação, com auditórios específicos.

Além da escolha pelos gêneros de discursos categorizados por Aristóteles - o deliberativo (que procura persuadir ou dissuadir), o judicial/forense (que acusa ou defende) e o epidêico/epidíctico (que elogia ou censura) -, Perelman e Olbrechts-Tyteca situam pontos de partida da argumentação. Entre eles estão os acordos, subdivididos em: a) Tipos de objeto de acordo (fatos e verdades, presunções, valores: abstratos e concretos) -, hierarquias, lugares (comuns, específicos, de quantidade, de qualidade) etc.; b) Os acordos próprios de certas argumentações (auditórios particulares, acordos próprios para cada discussão, argumentação 
ad hominen e a petição de princípio). Encaixam-se também neste item a apresentação dos dados e a forma do discurso, como a escolha das palavras, o tempo verbal, a expressão do pensamento (positivo e negativo), as figuras de retórica e de argumentação.

As condições para uma argumentação não prescindem do acordo com o auditório. Para que isso aconteça, Perelman e Olbrechts-Tyteca (p. 74) tratam em sua obra dos objetos dos acordos, que podem servir de premissas em duas categorias: uma relativa ao real, que inclui os fatos, as verdades e as presunções; e outra relativa ao preferível, que, ao contrário da categoria anterior, pretende a adesão de grupos particulares e, para isso, conta com os valores, as hierarquias e os lugares do preferível.

Os objetos de acordo relativos ao real visam à adesão do auditório universal e que um fato é algo comum a várias pessoas, ou seja, algo em que reina um acordo universal a seu respeito; as verdades são os elos entre os fatos e devem, portanto, transcender a experiência; e que as presunções, como estão ligadas à opinião, não conseguem, por si sós, ter adesão máxima do auditório, precisando, portanto, do reforço de outros elementos. $\mathrm{O}$ valor está ligado à ideia de multiplicidade dos grupos, de se atingir públicos particulares. Ao tratar deste tópico, os autores destacam (1996, p. 87) que há valores universais ou absolutos - tais como o Verdadeiro, o Bem, o Belo etc. -, valores abstratos e valores concretos.

Os autores (idem, p. 132) enfatizam ainda que, quando certos elementos são selecionados e apresentados ao auditório, estes elementos ganham presença. Esta presença é um dado psicológico que interfere diretamente sobre a sensibilidade de quem a vê. Isso significa que, se toda argumentação é seletiva e torna presente o fato selecionado, logo, toda argumentação é parcial. Em busca da solução para esta parcialidade, os pesquisadores recomendam (idem, p. 136) que uma argumentação tendenciosa seja completada pela argumentação adversa, a fim de permitir um equilíbrio. A etapa seguinte à seleção dos dados é a respectiva interpretação; é preciso dar-lhes sentido, torná-los relevantes para o seguimento do discurso, pois os termos utilizados se revelam sob vários modos de significação (idem, p. 137).

Em resumo: todo o movimento argumentativo consiste em transpor a adesão inicial que o auditório tem relativamente a uma opinião que lhe é comum para uma outra de que o orador o quer convencer, são as premissas da argumentação. Daí a importância do kairós ${ }^{3}$ e do conhecimento que o orador deve possuir do seu auditório, das suas opiniões, das suas crenças, enfim, de tudo aquilo que ele tem por admitido. 
Estas devem ser as premissas da argumentação para o estabelecimento do contexto retórico: as teses sobre as quais há um acordo. É claro que pode sempre ser utilizado o estratagema da petição de princípio, simulando tomar por acordado precisamente aquilo que se trata de demonstrar. No entanto não é esse o procedimento habitual.

\section{Encontro: a Retórica e o Jornalismo}

Os diversos empregos de ações retóricas e técnicas argumentativas são frequentes no dia a dia dos media, sendo necessário identificálos e averiguá-los. No Jornalismo, conforme refere Mesquita (2003, p. 337 ), muitas vezes os princípios retóricos são aplicados sem o pleno conhecimento de quem os pratica, embora os manuais jornalísticos disseminem técnicas que foram preconizadas na Antiguidade. Não obstante haver o pensamento de que a notícia, a priori, não se utiliza do processo retórico devido à objetividade na descrição do fato, predominando o modo de comunicação não intencionalmente persuasivo, a questão deve ser mais bem apreciada. Isso porque, para Grácio (1998, p. 49), a "factualidade não é dissociável de uma leitura ou interpretação (...) de que não há leituras neutras nem interpretações exclusivas."

Deste modo, presume-se que a retoricidade 4 esteja presente em boa parte do universo jornalístico, pois, como atribui Aristóteles à definição de retórica, "ela parece ser capaz de descobrir os meios de persuasão relativos a um dado assunto", mesmo que aparentemente esteja oculta. Assim, é plausível que o método de análise retórica, aplicado aos diversos campos da comunicação, possa contribuir para detectar ou não indícios de formas persuasivas na redação de uma notícia, em uma entrevista, em um debate, em uma reportagem ou em outros formatos jornalísticos. Com referência a esta particularidade, Mesquita (2003, p. 350) nota que "no domínio do estudo dos media, o legado retórico é um inesgotável repositório de conceitos que nos ajuda a equacionar as questões da comunicação nas sociedades contemporâneas."

Os mecanismos de retórica - e a própria retórica - estão presentes nos media de maneira clara e disfarçada, mas concorda-se com Leone (1997, p. 873), para quem "os media servem-se de formas redutoras e desvirtuadas do legado da retórica clássica". Para ele, "retórica é a arte do discurso", e da cisão entre a filosofia e a retórica resultou 
uma manifestação mais visível, mas, ao mesmo tempo, menos nobre, a oratória. Para Leone, "tudo parece indicar que a mediatização geral, acelerada e complexa das sociedades contemporâneas predispõe os meios de comunicação social a uma revalorização de uma série de expedientes retóricos". A estimativa vem se comprovando e a comunicação dos media - ou através dele - cada vez mais registra expedientes desta natureza no sentido de manter o público (o auditório midiático) fiel aos conteúdos expedidos pelos veículos impressos e eletrônicos.

Para Van Dijk (1990, p. 106), a retórica deve ser entendida num sentido amplo, como a disciplina que estuda todos os aspectos da fala ou da escrita persuasivas, destacando a importância do estudo do discurso para que se torne mais simples compreender os processos produtivos e os efeitos das comunicações. Isto é, "a análise do discurso abarca mais do que a mera descrição das estruturas textuais (...) o discurso não é só texto, é também uma forma de interação (...) uma análise extensa do discurso supõe uma integração do texto e do contexto no sentido de que o uso de um discurso em uma situação social é ao mesmo tempo um ato social."

Desta forma, para Américo de Souza (2002), o jornalismo é retórico, tendo em vista vários pontos de contato, pois "ao abandonar o acesso à pura factualidade, o jornalista centrasse nas tarefas de avaliação e debate, que o fazem retornar ao mundo da opinião, da intersubjectividade, do confronto". Em vista disso, se o que o jornalista informa é sempre e apenas a sua avaliação da realidade e nunca o fato em si mesmo, "então há necessidade de convocar uma argumentatividade que justifique e prove o acerto ou a preferência desta sua interpretação sobre outras interpretações igualmente possíveis". Ao mesmo tempo, o jornalismo é retórico por apelar para o regime da discutibilidade crítica e se decidir por uma avaliação com base no plausível e consensual, própria de toda a argumentação retórica.

Retórico porque se faz à custa de opções ou escolhas, quer na selecção dos factos a que atribui o valor de notícia, quer na própria construção desta última, opções ou escolhas que, como todos sabemos, nem são arbitrárias nem se fundam em razões universais ou logicamente coercitivas. Retórico, em suma, porque se trata de um conhecimento que emerge no contexto de uma comunicação marcadamente persuasiva onde o louvável espírito de isenção e objectividade não anula nem condena o propósito de atrair, de agradar e de conven- 
cer o respectivo auditório, enquanto principal alvo e razão de ser da actividade jornalística. É quanto basta, julgamos, para se reconhecer como o jornalismo partilha da relatividade do conhecimento retórico. Uma relatividade que não obriga, porém, a travar a marcha, a regressar ao ponto de partida ou a ficar pirronicamente de braços cruzados, só porque não há, afinal, um único caminho seguro para o verdadeiro conhecimento (...). Defender portanto que a verdade jornalística é argumentável ou retórica, já não pode surpreender ninguém. Nem o jornalista, nem o filósofo, nem o cientista. (SOUZA, 2002, p. 8-9).

Na obra La Retórica del Periodismo e otras Retóricas (1985), Francisco Ayala compara a retórica do jornalismo à retórica parlamentar, lembrando que o jornalismo é peça essencial da sociedade burguesa e das instituições políticas da democracia liberal e, portanto, essa base está presente nele. Por isso, o jornal - como produto do jornalismo - é um negócio a mais, a serviço de outros negócios, que quer

vender sus productos al público; pero en su caso estos productos son textos literarios, textos de la más diversa índole sin duda, pero portadores, todos ellos de algún tipo de mensaje; esto es, dirigidos a actuar de un modo u otro sobre la inteligencia y la conciencia del destinatario (...) el periódico es um negocio muy especial (...) pues no sólo vende ideas, sino que, al hacerlo, se convierte em lo que se ha denominado un órgano de opinión pública. (AYALA, 1985, p. 47-48)

Por se constituir em um veículo da opinião pública, o jornalismo apresenta o debate oratório das câmaras legislativas, tendo em vista que nelas se votam as leis e se decide a vida dos cidadãos. Esta retórica da persuasão e do convencimento, lastreada em argumentos e em recursos oratórios, transfere-se também para os media. Ayala (1985, p. 50) sustenta que esse gênero novo de retórica, a retórica do jornalismo, segue as linhas da antiga e ilustre retórica oratória, com a estrutura jurídica e forense, que objetiva desacreditar as razões dos adversários, impressionando o auditório e captando-o em favor das ideias próprias.

Em um artigo de fundo, por exemplo, ou em um texto literário, a estrutura da alocução está presente, seguindo a retórica parlamentar e oratória. Até chegar às conclusões para impressionar o leitor (ouvinte, telespectador, internauta), o orador busca justificá-las, utilizando-se, 
além dos argumentos, da estética, da emoção e da paixão. Além disso, a retórica parlamentar, a exemplo da retórica do jornalismo combativo, não quer tão somente sensibilizar a audiência. Conforme Ayala (1985, p. 52), ela se encaminha para obter resultados práticos imediatos. Uma retórica para a ação, "que quer (...) moverlo en una dirección pragmática, a convencerlo, a inclinarlo a la acción - por lo menos, a esa acción incoativa o potencial que supone un ánimo predispuesto em favor de cierta tesis”. Isto se aplica, em geral, à retórica do jornalismo, quando ao divulgar uma informação ou uma opinião, há intenções implícitas, ocultas e quem sabe até inconscientes de quem as transmite.

O efeito pode ser maior nos media eletrônicos (rádio, televisão, internet), nos quais o emissor e o receptor estão ligados praticamente no mesmo tempo histórico e, em alguns casos, podem até interagir. "La eficacia del discurso se alcanza en comunicación viva y actual, mientras que la eficacia del texto escrito depende de la virtud del mero razonamiento, recibido a través de la lectura; y ésta, eliminados los halagos y señuelos de la participación en un acto público, y hecha en sosegado aislamiento, impone una mesura mayor" (AYALA, 1985, p. 53).

Hoje, alguns veículos, sejam impressos ou eletrônicos, expressam-se com notícias curtas, rápidas de ler e, em alguma medida, superficiais. Esta forma de jornalismo, dito moderno e proposital, tende tão somente a enganar as pessoas que, ao ler, ouvir ou ver as notícias, em vários suportes, imaginam que estão suficientemente informadas sobre os fatos do momento.

As técnicas jornalísticas para atração e sedução, despertando a curiosidade, assemelham-se, em alguns casos e de certa maneira, à publicidade. Da mesma forma que esta, os jornalistas, que estão também influenciados pelo contexto sociopolítico e econômico no qual estão inseridos, através das técnicas de edição e de seleção das notícias, orientam as pessoas para que se fixem nas notícias apresentadas como mais ou menos importantes, despertando a novidade pela persuasão, pelo tipo e o corpo da letra definidos, pelo espaçamento, pelas margens, pela disposição das matérias, das fotos etc., almejando causar impacto.

Composto por muitas fórmulas prontas, o jornalismo tendencioso utiliza mecanismos do que Ayala define como a má retórica e seus riscos, ou como uma má aplicação da retórica. Pois, para ele, ao definir a melhor expressão para chegar-se ao grau de comunicação máxima ou escolher palavras que causem mais impacto na imaginação do leitor, não significa, a priori, o mau uso da retórica. Há outros enlaces presentes 
como o fato de algumas notícias serem transmitidas de modo anódino, aparentemente sem itenção e/ou interesse, e que não dão margem à análise reflexiva.

Para Silveirinha (2004, p. 136), "os media noticiosos produzem uma comunidade mais alargada, dando às pessoas possibilidades de conversarem". E cita Anderson, Dardenne e Killemberg (1994, p. 10-11) que atribuem ao jornalismo o fato de encorajar e contribuir na conversação das subcomunidades, "mas a sua principal missão é ligá-las a uma comunidade mais vasta”. A facilitação proporcionada pelos media não é pacífica, encontrando opositores que culpam os meios de massa por criarem muito mais barreiras do que facilitarem a comunicação.

\section{Proposta: a retoricidade de contexto}

A partir da pesquisa exposta até aqui é possível seguir as pistas deixadas por Aristóteles e ir além com a Retórica. Assim, se um leitor opta por determinado jornal, se um telespectador resolve assistir aquele programa ou o ouvinte uma emissora de preferência, não se pode dizer que neste ato não haja uma retoricidade presente. A informação ali está como uma garantia, uma certeza de que o leitor-telespectador-ouvinte ou internauta vai acompanhar a última notícia ou encontrar o que necessita naquele momento e naquela mídia. Compõe esta retoricidade as características da empresa, como o seu grupo de funcionários, a publicidade de si mesma, entre outros atributos de permanência da marca na mente do público; enfim, numa série de particularidades e ações que reforçam a imagem da empresa jornalística.

Um recurso muito comum das empresas jornalísticas é o uso de slogans. Os slogans exibidos com constância nas diversas mídias martelam junto ao público as ideias para sustentar uma filosofia de ação. Conforme Perelman e Olbrechts-Tyteca (1996, p. 189), "os slogans incentivam a ação" e impõem "ideias à nossa atenção”, e, até mesmo determinam crenças e tendem a criar um ambiente confiável.

Ao compor esta retoricidade de contexto, os media pensam na embalagem do conteúdo. No jornal, a diagramação, as cores. Na televisão, as vinhetas, as trilhas. No rádio, as cortinas, as características musicais. Vale aqui, de antemão, ser logo reconhecido pelo leitor-telespectador-ouvinte-internauta. A este processo de elaboração da embalagem, 
ainda podemos perceber a associação ao ethos, pathos e logos nos cânones retóricos. O colunista, no jornal. O âncora, na televisão. O apresentador, no rádio. São sujeitos conhecidos e reconhecidos pela população e que passam credibilidade à audiência.

Por todos estes aspectos, acredita-se ser possível implantar a AR no Jornalismo com o intuito de melhor detalhar onde, como e de que maneira a retoricidade está ali presente, mesmo oculta. Portanto, analisar retoricamente uma mensagem jornalística, não importando o meio em que esteja evidenciada, tem por objetivo aprofundar a investigação do emprego de ações que envolvam os atos de persuadir, de argumentar, bem como o uso das figuras de linguagem/figuras do discurso no contexto, na forma de apresentação ou no próprio conteúdo da mensagem.

\section{Referências}

ARISTÓTELES. Retórica. 3a. Edição. Obras completas de Aristóteles, Volume VIII, tomo I. Coordenação de Antônio Pedro Mesquita. Tradução de Manuel Alexandre Júnior, Paulo Farmhouse Alberto e Abel do Nascimento Pena. Lisboa: Imprensa Nacional-Casa da Moeda, 2006.

AYALA, Francisco. La retórica del periodismo y otras retóricas. Madrid: Espasa-Calpe, 1985.

BAUER, Martin W. e GASKELL, George. Pesquisa Qualitativa com texto, imagem e som. Manual Prático. Petrópolis: Vozes, 2002.

CARDOSO E CUNHA, Tito. Argumentação e Crítica. Coimbra: Minerva, 2004-a.

GRÁCIO, Rui Alexandre. Racionalidade Argumentativa. Porto: ASA, 1993.

. Consequências da Retórica: para uma revalorização do múltiplo e do controverso. Coimbra: Pé de Página, 1998.

LEACH,Joan. Análise Retórica.IN.: BAUER, Martin W.E GASKELL, George. Pesquisa Qualitativa com texto, imagem e som. Manual Prático. Petrópolis: Vozes, 2002.

LEONE, Carlos. Retórica e Oratória nos media. IN.: Congresso-A Retórica Greco-Latina e a sua Perenidade (Coimbra, 11-14 de março, 1997). 
José Ribeiro Ferreira (coord.). Edição da Fundação Eng. Antônio de Almeida, Porto, 200, II Vol.).

MEDITSCH, Eduardo. O rádio na era da informação - teoria e técnica do novo radiojornalismo. Florianópolis: Insular, 2001.

MESQUITA, Mário. O quarto equívoco: o poder dos media na sociedade contemporânea. 2a ${ }^{\text {a }}$ Edição. Coimbra: Minerva, 2004.

PERELMAN, Chaïm; OLBRECHTS-TYTECA, Lucie. Tratado da Argumentação: a Nova Retórica. São Paulo: Martins Fontes, 1996.

SANTOS, Boaventura de Souza. Introdução a uma ciência pós-moderna. São Paulo: Graal, 1989.

SILVEIRINHA, Maria João. Identidades, Media e Política: o espaço comunicacional nas Democracias Liberais. Lisboa: Livros Horizonte, 2004.

SOUZA, Américo de. Jornalismo e Retórica: as intersecções do possível. IN.: Comunicação apresentada no I Congresso Luso-Galego de Estudos Jornalisticos. Santiago de Compostela, Espanha, em 30 de Outubro de 2002.

VAN DIJK, A. La Noticia como discurso. Barcelona, Paidos, 1990.

\section{Notas}

[1] O artigo em questão teve idéias e partes extraídas do relatório "A Nova Retórica e o Rádio Informativo: o estudo das programações das emissoras TSF de Portugal e CBN do Brasil", apresentado em junho de 2009, como requisito de pós-doutoramento no Instituto de Estudos Jornalísticos (IEJ), da Faculdade de Letras, da Universidade de Coimbra.

[2] Para fins deste artigo, vai-se utilizar a obra em sua tradução para o português, o Tratado da Argumentação: a Nova Retórica (São Paulo: Martins Fontes, 1996).

[3] A boa análise retórica responde ao que os gregos clássicos chamaram de kairos e phronesis, termos que traduzidos de maneira vaga significam: kairos, a dimensão de tempo de um texto persuasivo; phronesis, a conveniência de um texto persuasivo específico (LEACH, 2002, p. 299).

[4] Emprego de ações retóricas que envolvem os atos de persuadir, de argumentar e o uso das figuras de linguagem/figuras do discurso. 
* Luciano Klöckner

Doutor em Comunicação

PUCRS e Pós doutorado na

Universidade de Coimbra/

Portugal. Jornalista e professor da Faculdade de $\mathrm{Co}^{-}$ municação Social (Famecos) da Pontifícia Universidade Católica do Rio Grande do Sul (PUCRS).

E-mail:

lucianoklockner@yahoo.com.br 